\title{
UMA ABORDAGEM DA HISTORIOGRAFIA BRASILEIRA DA SEGUNDA METADE DO SÉC. XIX ATÉ 1920
}

Charles Monteiro*

O objetivo deste artigo é analisar a produção do conhecimento histórico na historiografia sobre a história geral do Brasil, entre 1830 e 1920. A escolha do período justifica-se na medida que compreende uma importante fase de renovação da historiografia brasileira ocorrida com a fundação do Instituto Histórico e Geográfico, em 1839, e seus desdobramentos até a reformulação do paradigma historiográfico empreendido por Capistrano de Abreu.

Este esforço teórico que necessariamente impõe a redução da análise a alguns temas e sujeitos, procura compreender os elementos de conjunto e explicar as grandes linhas do amplo quadro de possibilidades aberto por essa problemática.

Considero que o status desta discussão encontra sua justificativa na medida em que se discute muito no ambiente acadêmico contemporâneo sobre a "crise" da ciência histórica e o "fim da história"; enquanto manifesta-se na realidade uma grande defasagem entre o saber produzido pelos "historiadores de ofício" e a vulgarização deste'saber ao nível do ensino médio e meios de comunicação. Logo, torna-se premente para a academia refletir sobre as suas práticas enquanto produtora de uma

* Professor do Departamento de História - IFCH-PUCRS 
memória social da e para a sociedade brasileira, bem como sobre a história do processo de construção desta memória na forma de um discurso histórico (historiografia).

A reflexão sobre a historiografia brasileira que se propõe realizar aqui está diretamente relacionada a noção da construção processual de uma "matriz" do conhecimento histórico, a partir da segunda metade do séc. XIX, no Brasil. Ou seja, refletir sobre a dinâmica da construção dos fundamentos de uma cultura histórica brasileira dentro de um referencial mais amplo que seria o da História da Cultura Brasileira (cf. Mota, 1980:17-25; Pecaut, 1990:14-18; Lapa, 1976).

A cultura histórica será entendida como as concepções a cerca da história de um conjunto de autores - não necessariamente "historiadores de ofício" - que apresentam, num determinado período, acima das suas características particulares e diferentes imediatas, uma unidade ou centralidade nos "temas" escolhidos e no tratamento destes "temas" em sua produção historiográfica, logo, na forma de pensar e representar o processo histórico.

No sentido de analisar a produção historiográfica desse período é preciso eleger algumas variáveis que permitam verificar a existência de uma "matriz" do conhecimento histórico e, assim sendo, analisar os elementos constitutivos da cultura acima, na forma de pensar e representar o processo histórico. Seriam estas variáveis ou elementos constituintes da cultura histórica: a) os interesses do conhecimento ou a preocupação-problema que impulsiona a produção de uma História do Brasil; b) a formação do historiador: ambientes acadêmicos e panorama institucional; c) o compromisso de classe e inserção social; d) vinculação com o Estado; e) as influências teóricas; f) as questões metodológicas; g) a forma de narrar a história e o estilo; h) o público leitor; i) o sentido da história.

Para abordar este largo período de tempo é melhor dividi-lo em duas grandes unidades, as quais correspondem a modificações significativas ocorridas na produção historiográfica sobre a História do Brasil, logo alterações da "matriz" do conhecimento histórico. A primeira unidade corresponde a formação do Instituto Histórico e Geográfico Brasileiro, tendo como maior expoente deste período Francisco Adolfo Varnhagen. A segunda unidade aborda as transformações ocorridas na virada do séc. XIX e o surgimento de novas orientações que se cristalizam 
na produção de Capistrano de Abreu, situado entre a herança de uma historiografia "tradicional" e suas influências "modernistas"; configurando um momento de transição rumo a historiografia da "geração de 1930", que promoveria uma "redescoberta do Brasil" baseada em novas influências teóricas e metodológicas. Os expoentes desta geração Gilberto Freyre, Caio Prado Júnior e Sérgio Buarque de Holanda estavam interessados em descobrir a Nação brasileira, na medida em que também era necessário constituir o Estado brasileiro. A contribuição desta "geração de 1930" será abordada em um artigo posterior.

\section{A HISTORIOGRAFIA BRASILEIRA NA SEGUNDA METADE DO SÉCULO XIX}

Embora José Honório Rodrigues (1979:426-438) salienta a importância na Historiografia Colonial de Pedro de Magalhães Gándavo com a História da Província de Santa Cruz (Lisboa, 1576) e Gabriel Soares de Souza com o Tratado Descritivo do Brasil em 1587 (1 $1^{\mathrm{a}}$ edição integral, em Lisboa, 1825) - este último considerado por Varnhagem "patriarca" da História do Brasil - as obras destes autores portugueses são crônicas gerais dedicadas a relatar a vida e a economia brasileira, sobretudo, acontecimentos contemporâneos a eles para os habitantes da metrópole para incentivar a colonização.

Até o começo do século XIX, uma das últimas obras sobre a história geral do Brasil, que se propunha a uma certa visão de conjunto, havia sido escrita por Rocha Pita (1660-1738). A História da América Portuguesa serviu de referencial a produção historiográfica brasileira por largo tempo.

Desde o título é perceptível que o interesse do conhecimento desta obra não está centrado na análise da formação da sociedade brasileira, pois esta narrativa de tipo exemplar buscou na lógica da transplantação da "civilização" portuguesa para os trópicos e no papel "civilizador" do conquistador português seu sentido primordial.

Sebastião da Rocha Pita estudou no Colégio dos Jesuítas da Bahia, onde entrou em contato com as letras e desenvolveu o gosto pela literatura. Rocha Pita pertencia a elite colonial, foi Coronel de Ordenanças da Corte de Salvador, cavaleiro da Ordem de Cristo, membro da 
Academia Real de História Portuguesa de Lisboa e sócio fundador da Academia Brasílica dos Esquecidos, tendo sido eleito posteriormente para o Senado da Câmara de Salvador (RODRIGUES, 1979:494). Torna-se então evidente sua estreita vinculação com o aparelho administrativo do Estado Colonial e a sua subordinação ao sistema de saber da Academia Portuguesa.

A obra não apresenta nenhuma preocupação metodológica com a veracidade da narrativa histórica, a crítica documental e, muito menos, em levantar uma problemática. A narrativa está baseada em relatos orais e documentação, porém não existe uma avaliação crítica da autenticidade, veracidade e adequabilidade das fontes. $\mathrm{O}$ autor encontra suas influências teóricas no Arcadismo e tem na prosa poética a sua marca de estilo. Tece um verdadeiro hino de louvor à terra e a o esplendor da natureza brasileira, ligando as conquistas realizadas pela civilização aqui às da Grécia Antiga, com o claro objetivo de dar provas de sua erudição. Estava mais preocupado com o reconhecimento da Academia Portuguesa do que na compreensão do processo histórico, poderia-se considerá-la uma novela histórica.

Robert Southey foi um dos principais críticos de Rocha Pita, afirmando na obra História do Brasil que a importância da História da América Portuguesa estava na falta de outra, pois tratava-se de obra "magra e mal alinhavada". O historiador britânico que se interessa pela história do Brasil por estar escrevendo uma História de Portugal e entender ser impossível compreender esta sem tomar em conta o Brasil como a fonte da riqueza e do prestígio de Portugal. Foi o primeiro a analisar o Brasil em relação ao contexto europeu e às colônias da América Espanhola, valendo-se de farta documentação existente nos arquivos europeus. Southey preocupa-se com a crítica das fontes e constrói uma narrativa mais realista ao apontar as dificuldades impostas pelo meio e pelos nativos à conquista do território brasileiro (Campos, 1977:254).

Entretanto, é a fundação do Instituto Histórico e Geográfico Brasileiro (IHGB), em 1839, que caracteriza este período e projeta raízes profundas na cultura histórica brasileira, produzindo e legitimando o discurso historiográfico ao longo de toda a segunda metade do séc. XIX. A mudança na matriz do conhecimento histórico estava intimamente ligada ao processo de emancipação política brasileira de Portugal. Era necessário escrever a história da nação brasileira, fornecer-lhe uma 
identidade, forjar um vínculo que unisse todas as realidades culturais $\mathrm{e}$ regionais, desligadas no período colonial, sob o poder do Estado Imperial. A necessidade de concenso político entre as oligarquias regionais deu origem ao mito fundador da nação: o indigenismo. Exalta-se o índio como ancestral e símbolo da nação livre emergente, idealizam-se as suas riquezas naturais através do nativismo; componentes esses fundidos a partir das influências teóricas do Romantismo. Foram os historiadores românticos franceses que forneceram este modelo de discurso que celebrava a formação da Nação (Campos, 1977:257).

A formação dos historiadores estava restrita a leitura não sistemáticas de pensadores europeus, ao autodidatismo e diletantismo, fruto do débil panorama institucional - não haviam escolas ou universidade dedicadas à formação de historiadores até a criação da Faculdade de Filosofia de São Paulo, em 1934 - e da inexistência de fronteiras bem definidas entre a arte da Retórica, a Literatura e a História que estava mais próxima de ser um gênero literário do que constituir um saber científico. Em geral, os historiadores eram advogados, médicos, funcionários do Estado que por sua erudição e "amor ao passado" arriscavam-se a incursionar pelo campo da História, reunindo-se nos Institutos Históricos e Geográficos nas províncias.

O discurso histórico desses historiadores estava visceralmente comprometido com as elites e oligarquias regionais a que freqüentemente pertenciam. Os institutos por eles criados e presididos tenderam a se encerrar numa erudiçâo acrítica, misto de academicismo e conservadorismo em sintonia com os interesses do Estado Imperial brasileiro.

$\mathrm{O}$ vínculo entre o IHGB e o Estado Imperial evidencia-se nos financiamentos fornecidos para o levantamento de fontes e na organização de "missões" para copiar coleções de documentos em arquivos europeus - como a de Gonçalves Dias, em 1863-64, e a de Ramiz Galvão, em 1873 - bem como, nas honrarias e títulos distribuídos a eles pelo Imperador.

O melhor exemplo desta geração de historiadores, que serviria para melhor compreendê-la em linhas gerais, apesar de afastar-se dela e da produção mais corrente do IHGB em alguns pontos, é o de Francisco Adolfo de Varnhagem com sua História Geral do Brasil, publicada, em 1847, c dedicada ao Imperador D. Pedro II (Varnhagen, s.d.). 
Vernhagen foi adido cultural brasileiro na Europa, o que lhe possibilitou pesquisar e coletar documentos em Portugal (1842-46), Espanha (1847), Holanda (1851), outros países europeus (1851-58) e Paraguai sob o mecenato do Estado Imperial. Filho de alemão, recebeu uma formação de influência européia, porém, ao contrário dos seus contemporâneos suas leituras dirigiram-no aos pensadores alemães e ao rompimento com o modelo dos historiadores franceses. Notadamente Ranke e o paradigma positivista, com o projeto de escrever e história tal como ela "aconteceu", foram referências teóricas para Varnhagen.

Este, abandonando todo resquício de romantismo não poupara críticas ao indigenismo e ao nativismo de Rocha Pita. Para ele o índio não era um herói romântico e a natureza mostrara-se hostil ao conquistador. Percebe-se também na obra de Varnhagen a influência do naturalista alemão von Martius. Martius estivera, no Brasil, entre 1818 e 1820, e elaborou em resposta a um pedido de subsídios do IHGB, um programa sobre a maneira correta de escrever uma História do Brasil. Esta ligação se evidencia na obra de Varnhagen - sendo notada inclusive por Capistrano de Abreu - no tema das três raças que através da miscigenação comporiam a Nação brasileira, bem como na preocupação de descrever o processo de povoamento, o desenvolvimento da lavoura, do comércio, dos ofícios e das ciências (CAMPOS, 1977:267).

Em termos metodológicos surge a preocupação heurística com a localização, levantamento, catalogação das fontes e os rudimentos de uma crítica de autenticidade e veracidade das fontes. Evidencia-se esta preocupação no incentivo a busca de fontes para escrever a história do Brasil nas províncias, pelos Institutos Históricos e Geográficos que são fundados nestas, e nas missões a Portugal e a outros países europeus (Espanha, Holanda) com o objetivo de reunir coleções documentais para integrar o acervo da Biblioteca Nacional. Seria Vernhagen, também, o primeiro a preocupar-se seriamente com a historiografia produzida pelos cronistas do período colonial.

A forma de narrar a história dos historiadores do IHGB e de Vernhagen caracteriza-se pela descrição do tipo factual, uma histórica tradicional no sentido de legitimar as raízes oligárquicas e elitistas da identidade do Estado brasileiro que estes historiadores se empenham em construir. Agem segundo uma "razão ornamental" que destituida de 
senso crítico não problematizava o processo conflituoso e os diferentes projetos para construir a nação brasileira.

Em Varnhagen, por exemplo, não se encontra uma síntese a respeito do processo de formação da sociedade brasileira, pois os assuntos são tratados de forma individualizada e desligada de um plano de conjunto, de um todo mais abrangente e esclarecedor da inter-relação entre os vários processos em questão. Em momento algum existe um questionamento a respeito da sociedade escravista e do domínio político dos grandes proprietários de terras em oposição à miserabilidade da maioria da população; para ele esta organização política do Império e a instituição da escravidão eram evidentes e necessárias.

Mas, afinal, quem era o público leitor desta produção historiográfica? Certamente o discurso historiográfico que pretendia estabelecer as bases históricas da formação da identidade e da naçāo brasileira visava, em primeiro lugar, conscientizar e forjar o consenso no seio da própria elite. Era uma fração desta elite política, das oligarquias rurais regionais, que detentora do saber, no Brasil Império, consumiu esse discurso veiculado pela academia através da Revista do IHGB e dos Institutos Históricos e Geográficos provinciais. Grande parcela da população continuava marginalizada em relação ao acesso ao saber histórico produzido pelos eruditos membros do IHGB, que permaneciam encerrados em uma "torre de marfim" onde os 'barulhos' vindos da rua e da multidão não atrapalhavam seu nobre "oficio".

\section{CAPISTRANO DE ABREU REFORMA A MATRIZ DA CULTURA HISTÓRICA}

Foi no último quarto do século XIX que começaram a ocorrer mudanças neste quadro. Capistrano de Abreu seria o responsável pelo estabelecimento de um novo marco em nossa historiografia através da ampliação dos alicerces estabelecidos por Varnhagen e da revisão crítica dos fundamentos da cultura histórica brasileira.

Capistrano iniciou sua formação intelectual em um cenário político agitado por novas idéias e pela movimentação das camadas médias urbanas em plena crise do Império. Em 1869, em Recife, começou a cursar Direito e estudar francês e inglês, terminando por dedicar-se à História $\mathrm{e}$ 
abandonar os estudos jurídicos. Transfere-se, posteriormente, para Fortaleza onde ingressou num grupo de jovens intelectuais positivistas que se auto denominava Academia Francesa. Porém, a partir de 1875, com a dispersão do grupo, Capistrano ampliaria o seu leque de influências teóricas através do contato com as filosofias de Spencer, Taine e Buckle (Campos, 1977:274).

Em 1879, no Rio de Janeiro, ingressava na Biblioteca Nacional onde toma contato com uma farta documentação a respeito da História do Brasil. Em 1883, prestaria concurso com a tese Descobrimento do Brasil e seu desenvolvimento no século $X V I$ e ocuparia a cátedra de História do Brasil do Colégio Pedro II (Rodrigues, 1963:x).

Capistrano dedicou-se especialmente à pesquisa, preocupando-se em tomar conhecimento do que era publicado na Europa, em especial, dos autores alemães. Dentre estes destacam-se os estudos de Geografia de Ratzel, que traduziu para o português. É perceptível a influência do plano de von Martius na preocupação com a Geografia, nos estudos das linguas indígenas e do processo de povoamento. Foi um continuador e crítico da obra de Varnhagen.

É a oportunidade oferecida pela Livraria Laemmert, em 1900, de revisar para uma nova edição o texto da História Geral do Brasil de Varnhagen, escrevendo notas e comentários ao texto, que lhe permite realizar uma intensa pesquisa a ter contato com novos documentos. A preocupação com a crítica da historiografia produzida é uma constante em Capistrano. Deste trabalho e da experiência e conhecimento adquirido no fértil período que trabalhara na Biblioteca Nacional surgiriam, em 1907, os Capítulos de História Colonial, a obra mais completa, profunda, objetiva e crítica escrita até então sobre o período colonial.

As preocupações metodológicas de Capistrano ẹtavam muito além das dos seus contemporâneos. Preocupou-lhe não só a fase heurística da pesquisa, em que tornou-se especialista com a crítica e atribuição de autoria de documentos, mas na reflexão sobre as possibilidades de conhecimento das fontes, desenvolvendo seu discurso historiográfico baseado em uma problemática. Relacionou a História do Brasil à História de Portugal e da Europa, compreendendo as necessidades européias na realização das navegações. Estabeleceu uma periodização para o estudo da história colonial seguindo até o presente. 
Em sintonia com as novas tendências européias, críticas de herança do Romantismo e defensoras do Realismo (Flaubert, 1857) e do Naturalismo (Zola, 1885) na Literatura - como, Machado de Assis e Aluísio de Azevedo, em 1881, no Brasil - Capistrano apresenta uma visão desapaixonada do índio e uma perspectiva realista e científica do meio geográfico.

Sua forma de narrar é sintética, objetiva e fluente, apesar de descritiva, com a preocupação de apresentar um plano de conjunto sobre a formação do Brasil. Não se encontra nos Capítulos a constante referência a nomes e datas que caracterizava a produção de vários historiadores. Contudo, é possível identificar nele o tema das três raças, um certo determinismo psicológico destas e do meio, bem como a inexistência de uma crítica ao domínio das elites rurais, à instituições da escravidão, assim como não destacava a importância dos movimentos sociais de rebeldias à ordem constituída. Vê-se, então, que Capistrano "modernizou" o discurso historiográfico através de inovações metodológicas e novas influências teóricas, mantendo vínculos com a "tradição" na medida em que não analisou os movimentos sociais e caracterizou as diferenças de classe como raciais.

De uma forma diferente a dos historiadores do IHGB, que veicularam sua produção exclusivamente através da Revista do IHGB, Capistrano escreveu artigos para vários jornais atingindo um público leitor pertencente às camadas médias urbanas, democratizando assim um pouco o saber histórico.

Capistrano foi o expoente de uma geração da qual fizeram parte nomes importantes como Rio Branco com Effemérides Brasileiras, Joaquim Nabuco com Minha Formação (todos os dois influentes políticos), Pandiá Calógeras com Formação Histórica do Brasil e Euclides da Cunha com os Sertões, marcada pela decadência do Império, pelas lutas abolicionistas e pela ascensão de novos atores sociais na cena política. Como herdeiro destes poderia-se arrolar Paulo Prado com $O$ Retrato do Brasil que situa-se como o avesso da obra de Rocha Pita.

Concluindo, ao longo do século XIX, a matriz da cultura histórica brasileira esteve marcada pela tentativa de fornecer uma identidade à nação emergente e elaborar um discurso histórico que legitimasse o consenso entre as elites regionais através da restituição de uma herança histórica de dominação comum a todas as regiōes e através da imagem "libertária" do índio. Os produtores deste discurso historiográfico eram, em geral, autodidatas sem nenhuma formação especial adquirida 
formalmente em Universidades ou Academias para exercerem esse metier. Os historiadores estavam intimamente ligados, através do financiamento e da concessão de cargos, ao Estado Imperial e à elite composta pelos grandes proprietários de terras e escravos, que dominavam a política ao nível regional. As suas preocupações metodológicas se limitaram na fase heurística da pesquisa, na procura, classificação e organização das fontes e documentos. A crítica às fontes surge com Varnhagen, mas o levantamento de problemas e a utilização de conceitos tardariam a ser introduzidos. A forma de narrar era descritiva, factual e linear dos acontecimentos que não se preocupava em estabelecer relaçōes mais gerais de causalidades com a totalidade mais abrangente, a história Européia e Ocidental por exemplo. $\mathrm{O}$ estilo foi freqüentemente o romântico, que projetou a Nação sobre a figura heróica do indígena. O público leitor era composto pela própria elite política imperial e oligarquias provinciais e o sentido deste discurso historiográfico foi o de obter o consenso entre as várias frações de classe da elite imperial visando o projeto de constituição da Nação e do Estado Imperial.

Entretanto, a partir de Capistrano de Abreu, que mantendo elementos desta cultura histórica "tradicional" introduz uma nova metodologia, ocorreria um salto qualitativo rumo ao discurso historiográfico "moderno" da "geração de 1930". Discurso este que será tema de um outro artigo, a ser publicado, em breve, nesta mesma revista.

\section{BIBLIOGRAFIA DE REFERÊNCIA}

ABREU, Capistrano de. Capítulos de história colonial (1500-1800) \& os caminhos antigos do povoamento do Brasil. 5. ed. Brasília: Editora da Universidade de Brasîlia, 1963.

CAMPOS, Pedro Moacyr. Esboço da Historiografia Brasileira. In: GLENISSON, Jean. Iniciação aos estudos históricos. 2. ed. São Paulo: DIFEL, 1977.

LAPA, J.R. Amaral. A História em questão. Historiografia brasileira contemporânea. Petrópolis: Vozes, 1976.

MOTA, Carlos Guilherme. Ideologia da cultura brasileira: 1933-1974. São Paulo: Ática, 1980. PECAUT, Daniel. Os intelectuais e a politica no Brasil. São Paulo: Ática, 1990.

PITA, Sebastião da Rocha. História da América portuguesa. Belo Horizonte: Itatiaia; São Paulo: Editora da Universidade de São Paulo, 1976.

RODRIGUES, José Honório. Introduçăo. In: ABREU, Capistrano de. Capitulo de história colonial (1500-1800) \& ... 5. ed. Brasilia: Universidade de Brasília, 1963.

. História da História do Brasil. São Paulo: Nacional/INL/MEC, 1979.

SOUTHEY, Robert. História do Brasil. 4. ed. São Paulo: Melhoramentos/INL/MEC, 1977.3v.

VARNHAGEN, Francisco Adolfo. História geral do Brasil. 4. ed. São Paulo: Melhoramentos, s.d. 4v. 